\title{
Retraction Note: Investigation of remote sensing image and big data analytic for urban garden landscape design and environmental planning
}

\author{
Min Wang ${ }^{1}$
}

Published online: 6 December 2021

(c) Saudi Society for Geosciences 2021

Retraction Note to: Arabian Journal of Geosciences (2021) 14: 473 https://doi.org/10.1007/s12517-021-06795-Z

The Editor-in-Chief and the Publisher have retracted this article because the content of this article is nonsensical. The peer review process was not carried out in accordance with the Publisher's peer review policy. The author disagrees with this retraction.

The original article can be found online at https://doi.org/10.1007/ s12517-021-06795-z.

Min Wang

wangmin19812020@163.com

1 Nanyang Institute of Technology, Nanyang 473000, Henan, China 